\title{
Mucinous Gastric Adenocarcinoma with Morphological Change from Polypoid to Depressed Lesion within a Short Period
}

A 55-year-old woman was admitted to hospital with epigastric discomfort and generalized weakness of 2 months' duration. On physical examination there was a mass on palpation in the thyroid area. Esophagogastroduodenoscopy (Figure 1) revealed a polypoid lesion on the lesser curvature of the antrum. At 2 weeks later, when we performed esophagogastroduodenoscopy (Figure 2) for polypectomy, we found a depressed lesion where previously the polypoid lesion had been located. Histopathological evaluation of the endoscopic biopsy specimen disclosed a well-differentiated adenocarcinoma. Endoscopic ultrasonography (EUS) revealed a hypoechoic mucosal thickening with an internal anechoic cystic area in the lateral margin of the lesion. Because the patient refused operation, endoscopic mucosal resection was carried out. Histopathological evaluation of the endoscopic mucosal resection specimen (magnification $\times 200$ ) disclosed mucin pools including a welldifferentiated adenocarcinoma which invaded the muscularis mucosa and a considerable part of the submucosa. Although she was scheduled to return for operation 2 months later, we were not able to follow up this patient any further.

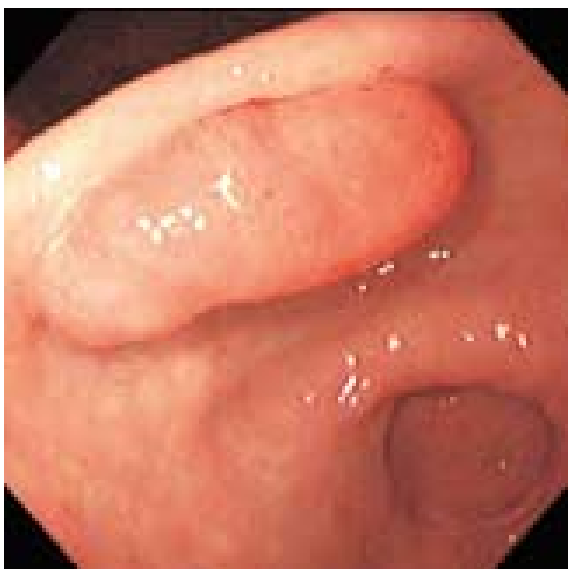

Figure 1 Esophagogastroduodenoscopy showed a polypoid lesion with an irregular surface, on the lesser curvature of the antrum.
Mucinous gastric adenocarcinoma is a rare subtype of gastric adenocarcinoma which comprises approximately 3-5\% of all gastric carcinomas [1]. The terms mucoid, colloid, or gelatinous have been used by different authors to describe this carcinoma subtype [2]. Although this histological subtype has long been recognized, its characteristics have seldom been reported. Whether mucinous gastric carcinoma behaves as aggressively as a mucinous colorectal carcinoma is still controversial [3]. While some studies have supported a worse prognosis when there is mucin content [4], others have reported an indolent presentation [2] or refuted any difference [1]. However, there has been no report about the characteristic of morphological change in the same lesion of mucinous adenocarcinoma. The present case demonstrated a mucinous gastric adenocarcinoma with a morphological change from polypoid to depressed lesion within a short period, which was diagnosed histologically after endoscopic mucosal resection.

\section{B. Ryu, J. Y. Cho, J. S. Lee, M. S. Lee, S. Y. Jin, C. S. Shim} Institute for Digestive Research, Digestive Disease Center, Soon Chun Hyang University College of Medicine, Seoul, Korea

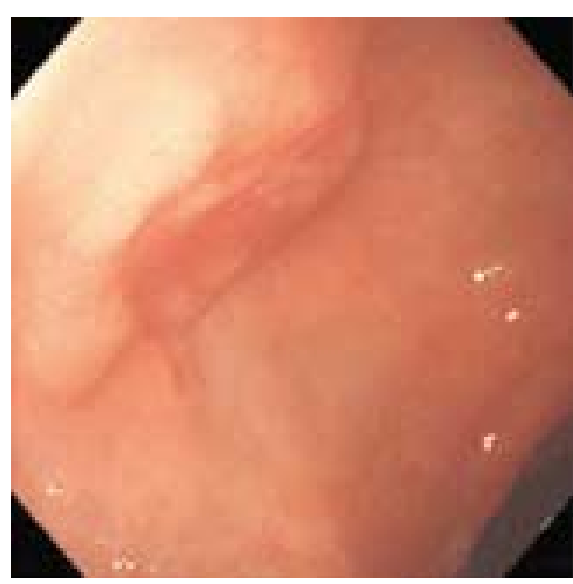

Figure 2 At the same location 2 weeks later, follow-up esophagogastroduodenoscopy showed a depressed lesion with redness and an irregular base and margin.

\section{References}

${ }^{1}$ Adachi Y, Mori M, Kido A et al. A clinicopathologic study of mucinous gastric carcinoma. Cancer 1992; 69: 866-871

2 Brander WL, Needham PRG, Morgan AD. Indolent mucoid carcinoma of stomach. J Clin Pathol 1974; 27: 536-541

${ }^{3}$ Wu C-Y, Yeh H-Z, Shih RT, Chen G-H. Intraluminal mucin pool in mucinous gastric adenocarcinoma: a case report. Chin Med J (Taipei) 1998; 61: 673-677

${ }^{4}$ Hoerr So, Hazard JB, Bailey D. Prognosis in carcinoma of the stomach in relation to the microscopic type. Surg Gynecol Obstet 1966; 122: $485-494$

\section{Corresponding Author}

\section{C.-S. Shim, M.D.}

Digestive Disease Center

Soon Chun Hyang University Hospital 657 Hannam-Dong

Yongsan-Ku

Seoul 140-743

Korea

Fax: $\quad$ + 82-2-7491968

E-mail: schidr@hosp.sch.ac.kr 